\title{
SECRETUM SECRETORUM: O LUGAR DO ESOTERISMO NAS CORTES PAPAL E IMPERIAL NO MEDIEVO*
}

\author{
SECRETUM SECRETORUM: THE ESOTERICISM PLACE'S IN THE PAPAL AND IMPERIAL COURTS IN THE MIDDLE AGES
}

\author{
Francisco de Paula Souza Mendonça Junior** \\ kirijy@gmail.com
}

RESUMO: O presente artigo discutirá o lugar das concepções esotéricas nas relações de poder em algumas cortes medievais. Foi escolhida como objeto de discussão a obra Secretum Secretorum, o Segredo dos Segredos, texto no qual Aristóteles daria conselhos de governo a Alexandre, o Grande, conselhos esses de teor esotérico. A análise está centrada em dois grandes eixos, sendo eles sua circulação entre as cortes imperial e papal, como também as temáticas das quais tratava tal obra. Acreditamos que a reflexão acerca do trânsito de tal livro entre essas duas cortes medievais, bem como o conhecimento a ele atribuído podem colaborar para ampliar a discussão acerca do papel do esoterismo como ferramenta aplicada nas relações de poder envolvendo interesses papais e imperiais. Compreendendo o esoterismo como instrumento de hierarquização social, onde o seu conhecimento ou a sua ignorância seriam capazes de causar distinção entre os homens, entendemos que o Secretum Secretorum, e o poder atribuído aos seus ensinamentos, estavam inseridos nessa dinâmica de relações de poder voltadas a separar os homens entre "aqueles que não podem saber" e "aqueles que podem saber".

PalaVRAs-ChaVe: Medievo, Poder, Esoterismo.

ABSTRACT: The present article will discuss the place of esoteric conceptions in the relations of power in some medieval courts. For this purpose the Secretum Secretorum, the Secret of Secrets, was chosen as the object of discussion, a text in which Aristotle would give advice to Alexander the Great, councils of esoteric content. The analysis is centered on two main axes, being their circulation between the imperial and papal courts, as well as the themes of which this work was treated. We believe that the reflection about the transit of such a book between these two medieval courts, as well as the knowledge attributed to it, can help to broaden the discussion about the role of esotericism as an applied tool in the relations of power involving papal and imperial interests. Understanding esotericism as an instrument of social hierarchy, where its knowledge or ignorance would be capable of distinguishing between men, we understand that the Secretum Secretorum, and the power attributed to its teachings, were embedded in this dynamics of power relations aimed at separating men between "those who cannot know" and "those who can know".

KEYWORDS: Middle Ages, Power, Esotericism.

As relações traçadas por homens como o abade alemão Johannes Trithemius (14621512) e o italiano Giambattista della Porta (c.1535-1615) entre esoterismo e política, através da forma como lidaram com o segredo em obras que marcaram época², não foram lançadas

\footnotetext{
${ }^{*}$ Texto baseado em trabalho apresentado no Congresso Internacional de História da Universidade Federal de Santa Maria, a partir de discussões oriundas da tese de doutoramento intitulada $A$ arte do segredo: esoterismo, sigilo e dissimulação política nos séculos XV e XVI (UFMG, 2014)

** Professor adjunto do Departamento de História da Universidade Federal de Santa Maria. Doutor e Mestre em História e Culturas Políticas/UFMG. Codiretor do Centro de Estudios sobre el Esoterismo Occidental de la UNASUR. Coordenador do Virtù - Grupo de História Medieval e Renascentista. Diretor da Revista Melancolia Revista de História do Centro de Estudios sobre el Esoterismo Occidental de la UNASUR.

2 Giambattista della Porta escreveu o tratado de comunicação secreta intitulado De Furtivis Literarum Notis vulgo De Ziferis (1563), já o alemão Johannes Trithemius escreveu a Polygraphiae libri sex (1518) e a Steganographie: Ars per occultam Scripturam animi sui voluntatem absentibus aperiendi certu, escrita por volta do ano 1500 e publicada pela primeira vez em 1621, ambas sobre escrita secreta.
}

Hist. R., Goiânia, v. 22, n. 1, p. 4-18, jan./abr. 2017 
em solo virgem. A verdade é que já havia alguns séculos que a relação entre o esoterismo e a política era uma possibilidade nas cortes europeias. Um dos exemplos mais marcantes disso foi a proliferação do Secretum Secretorum, o Segredo dos Segredos, texto pseudoaristotélico glosado por Roger Bacon (ca. 1220-1292). Conforme Patricia Eberle (1987, p. 435), trata-se de uma obra pautada pelo esoterismo cujo objetivo era transmitir conselhos sobre a arte de governar e conhecimentos esotéricos, supostamente transmitidos entre Aristóteles e Alexandre, o Grande.

De acordo com Steven William (1994, p. 127), o Secretum Secretorum foi um dos livros mais lidos da Idade Média, sendo tão ou mais popular do que os escritos genuínos de Aristóteles. Conforme Karma Lochrie (1999, p. 99-100) a sua popularidade pode ser atestada pelos mais de seiscentos manuscritos disponíveis, bem como por suas traduções em vernáculo, podendo ser encontradas versões em inglês, italiano, francês, alemão, hebraico, turco, russo, tcheco, croata, islandês, castelhano e catalão, além de conversões de prosa para verso. A autora ainda aponta que o Secretum Secretorum aparece em tratados ingleses sobre a coroação de reis, incluindo as coroações de Richard II e Edward IV. O tratado ainda foi incorporado em Geoffrey Chaucer (c.1343-1400), John Lydgate (c.1370-c.1451) e Thomas Hoccleve (c. 1368-1426), que inseriu a tradução para o inglês de um excerto do Secretum Secretorum em seu Regement of Princes (LOCHRIE, 1999, p. 115-116).

De acordo com Lochrie (1999, p. 100-101), a tradição secreta como modelo de transmissão de conhecimento não possuía origem ocidental, mas oriental. Assim, a literatura de segredos que surge no século XII no Ocidente, como diversas outras formas de conhecimento literário, teve suas origens na cultura árabe, especialmente no esoterismo islâmico. A criação da escola de tradutores em Toledo, por volta do século XII, permitiu que essa tradição islâmica do segredo se tornasse disponível no Ocidente, uma vez que essa conquista levou vários intelectuais medievais a buscarem pelos "segredos perdidos da Antiguidade", que teriam sido preservados na cultura árabe. O Secretum Secretorum foi muito influenciado por esse contexto, ainda que a intervenção de Roger Bacon tenha obscurecido suas raízes islâmicas. Sobre as origens árabes do Secretum Secretorum, Lochrie (1999, p. 101) nos apresenta os seus antecedentes árabes:

Os textos latinos do século XII do Segredo dos Segredos e as traduções posteriores foram baseadas em uma versão árabe do século $X$, Kitab SirralAsrar (Livro do Segredo dos Segredos), à qual o tradutor do século IX, Yahya 
ibn-al-Bitriq (João filho do Patrício ou de Patrício), afirmou ter traduzido para o siríaco a partir de um original grego perdido e então para o árabe. Enquanto as versões árabes sobreviveram em 50 manuscritos, as versões grega e siríaca não sobreviveram. Versões árabes maiores e mais curtas do Sirr produziram as duas linhas principais das recensões latinas do tratado dos quais ambas as edições manuscritas e traduções foram feitas. (LOCHRIE, 1999, p. 101) ${ }^{3}$

Conforme Williams (1994, p. 127-128), a primeira aparição do Secretum Secretorum na Europa foi em boa parte responsabilidade de João de Sevilha (c.1090-c.1153), que traduziu a seção médica desse tratado para a rainha espanhola Teresa, por volta de 1130 . A versão completa do tratado só surgiria em 1220, através de um clérigo chamado Philip de Tripoli, que durante uma visita à Antioquia junto com seu superior, o bispo de Tripoli, teria encontrado uma versão árabe do Secretum Secretorum, que foi vertida ao latim a mando de seu superior. Entretanto, devido à escassez de evidências é tarefa difícil afirmar com exatidão qual foi a porta de entrada do Secretum Secretorum na Europa. Para Williams, a resposta possivelmente mais acertada é aquela que leva em consideração um "mundo cultural compartilhado entre as cortes papais e imperiais".

O manuscrito mais antigo da tradução de Philip foi encontrado no caderno pessoal do curialista e agente papal Albert Behaim. Este caderno foi escrito pelo secretário pessoal de Albert durante a estada deste em Lyon, por volta de 1245 , na época do grande concílio que teve lugar nesta cidade. Junto ao Secretum Secretorum estavam notas e correspondências pessoais de Albert, além de uma miscelânea de textos e cartas oficiais, estando o tratado agrupado com material datado de 1245 . Williams considera mais provável que o exemplar do Secretum Secretorum à disposição de Albert tenha vindo do ambiente papal-imperial, mais precisamente da Universidade de Paris, onde ele afirma com certeza que havia um exemplar da obra neste período. Outra aparição antiga do Secretum Secretorum em sua versão completa ocorreu no mesmo milieu curial, pelas mãos do enigmático autor do tratado médico De retardatione accidentium senectutis, conhecido como "Dominus Castri Goet". Seu trabalho, que cita a tradução de Philip por duas vezes, sobreviveu até nós em duas versões: uma mais breve e outra mais longa. Williams estima

\footnotetext{
${ }^{3}$ The twelfth-century Latin texts of the Secret of Secrets and later translations were based on a tenth-century Arabic version, Kitab Sirral-Asrar (Book of the Secret of Secrets), which the ninth-century translator, Yahya ibnal-Bitriq (John son of the Patrician or of Patrick), claims to have translated from a lost Greek original to Syriac and then into Arabic. While the Arabic versions survives in 50 manuscripts, the Greek and Syriac versions do not. Long and short Arabic versions of the Sirr produced the two main Latin recessions of the treatise from which both Latin manuscript editions and translations were made.
} 
que ele teria escrito tais versões entre 1230 e 1240 . Na versão curta o autor informa que foi apressado a escrever seu trabalho por dois sábios de Paris, Johannes Castelloniatus e Felipe, o Chanceler de Paris. Felipe se tornou chanceler entre 1217 e 1236, ano de sua morte. Johannes Castelloniatus foi identificado por Agostino Paravicini Bagliani como Johannes Castellomata, magister et medicus papae, ${ }^{4}$ que testemunhou o casamento de Marie, Contessa de Montpelier e esposa de Pedro II de Aragão, que ocorreu na corte papal em 1213. Possivelmente trata-se do mesmo Johannes Castellomata que se tornou bispo de Policastro em 1254 e morreu em 1258. Para Williams o "Dominus Castri Goet" escreveu seu trabalho em terras italianas, porque o autor faz diversas referências a passar um tempo perto de Roma, e a várias personagens italianas e alemãs, contudo nenhuma francesa, indicando conexões com a corte imperial. Além disso, a posição de Castellomata de medicus papae e o fato de ser membro da influente família salernitana de Castellomata indicariam que ele manteve laços estreitos com a corte papal por toda sua vida. Felipe, o Chanceler de Paris, por sua vez, fez várias viagens à Itália - 1216, 1219, 1228 e possivelmente em 1230 e 1233. É certo apenas que "Dominus Castri Goet" escreveu depois de 1217, data provável em que Felipe teria se tornado chanceler (WILLIAM, 1994, p. 128-131).

De acordo com William (1994, p. 138-140) a primeira notícia do Secretum Secretorum no Ocidente se deu na corte de Frederico II da Germânia (1194-1250). Sua corte foi um dos grandes centros europeus de estudo, tradução e difusão do corpus aristotélico nessa época. Em 1224 Frederico II, o Stupor mundi, criou em Nápoles uma universidade que desde seu começo estava conectada à corte imperial. Williams diz que à época, para que uma universidade pudesse possuir mestres e doutores no corpo docente de cada faculdade, deveriam estar incluídos ao menos dois filósofos naturais aristotélicos e um professor de lógica. Frederico II, um "estudioso de filosofia" como o definiu um cronista do século XIII, possuía um interesse tão profundo no assunto que teria levado seu tutor muçulmano consigo durante a sua participação nas Cruzadas em 1228, a fim de poder dedicar-se aos estudos e reflexões sobre Lógica. Todo esse interesse do imperador em filosofia, especialmente nas discussões aristotélicas, criava o cenário ideal para a recepção do pseudoaristotélico Secretum Secretorum.

\footnotetext{
${ }^{4}$ Mestre e medico papal, tradução nossa.
} 
É controversa a maneira pela qual o Secretum Secretorum teria penetrado na corte de Frederico II. Alguns pesquisadores acreditam que a corte papal foi essa via de acesso. Apesar das tensões constantes entre o Império e o Papado havia uma comunicação constante entre as duas cortes, não apenas de trocas diplomáticas, mas envolvendo visitas de enviados de grande importância. Durante o período considerado por Williams, entre 1220 e 1235, tais embaixadas estiveram a cargo de homens como os cardeais John Colonna, Otto de Tonengo e Thomas de Cápua e da parte de Frederico II, pelo Grão-Mestre da Ordem Teutônica Herman de Salza e Jacob, arcebispo de Cápua. Todos estes homens gozaram da confiança do imperador e do papa. Williams afirma que muitos dos altos oficiais do imperador e do papa se conheciam pessoalmente, chegando alguns pesquisadores a classificar a relação entre o papa e o imperador como uma amizade. É verdade que a cruzada de Frederico II trouxe estranhamentos entre o papa e o imperador no período de 1227 a 1230, mas as relações amistosas retornaram com a Paz de Ceprano (1230). Não muito depois os dois líderes celebraram juntos em um banquete que durou três dias, no palácio papal de Anagni, e Frederico II passou mais um período com o papa, em 1234, na cidade de Rieti. Havia assim uma atmosfera mental compartilhada pelas duas cortes, uma vez que eram formadas por homens de mesmo ambiente cultural. Eles compartilhavam ideias, interesses e também livros. Foi igualmente comum que se trocasse de patronato, ou mesmo usufruir o patronato papal e o imperial simultaneamente, como fez Peter Paparonus. Sendo assim havia inúmeros acessos possíveis através dos quais o Secretum Secretorum poderia chegar à corte de Frederico II. Uma cópia também poderia ter sido providenciada no Levante e levada para Roma por algum dos inúmeros viajantes que percorriam o trajeto entre a Cidade Eterna e a Terra Santa. O próprio Philip, tradutor do Secretum Secretorum para o latim, poderia ter presenteado o papa Gregório IX com uma cópia dessa obra por ocasião de sua viagem a corte papal em 1230 . Inclusive algum membro da corte papal poderia ter presenteado o imperador com uma cópia desse tratado, sabendo que era o tipo de presente que satisfaria o Stupor mundi. Enfim, não faltavam caminhos entre a corte dos Hohenstaufen e a corte papal para o trânsito do Secretum Secretorum (WILLIAMS, 1994, p. 140-142).

Outro caminho que o Secretum Secretorum pode ter tomado para penetrar a corte de Frederick II seria vindo diretamente da Terra Santa, por meio das conexões de Frederico II 
no Oriente. Entronado em 1223, casado em 1225 com Isabel de Brienne, filha do rei de Jerusalém, Frederico II herdou o título e a responsabilidade sobre a Terra Santa, que ele intencionava cumprir, tanto que em 1226 ele colocou seus próprios bailiffs para governar a Terra Santa em seu nome. O próprio Frederico II lá esteve entre setembro de 1228 e maio de 1229, ocasião na qual poderia ter procurado pelo Secretum Secretorum. Frederico II também poderia ter conseguido a obra por meio de um de seus contatos poderosos na região, como Albert, Patriarca de Antióquia (1226-1246) e Bohemund IV, príncipe de Antióquia e conde de Trípoli. Em função do conjunto das fontes, é tarefa difícil definir aonde e por qual caminho o Secretum Secretorum chegou ao Ocidente. Independentemente se foi através da corte papal ou da imperial, o importante é que uma vez numa dessas cortes, ele rapidamente se difundiu para a outra, graças aos inúmeros e profundos laços que uniam a ambas, formando um mesmo universo cultural. Essa recepção no ambiente intelectual papal e imperial foi fundamental para o sucesso do Secretum Secretorum no Ocidente, uma vez que Ihe forneceu as credenciais intelectuais necessárias para sua subsequente trajetória de sucesso por toda a Europa medieval (WILLIAMS, 1994, p. 142-144).

Após essa breve reflexão acerca da primeira recepção do Secretum Secretorum na Europa, bem como de sua popularidade nas cortes, devemos pensar sobre o que tornou tal tratado tão popular entre uma audiência tão seleta. Um dos principais comentadores do Secretum Secretorum durante a Idade Média, se não o mais importante entre eles, Roger Bacon (1214-1294), monge franciscano e filósofo, entendia que uma das principais funções dessa obra era separar os sábios da multidão ignara, como também proteger o selo divino que governava todo o conhecimento científico. Para Bacon, o conhecimento contido no livro do Pseudo-Aristóteles, bem como em toda a filosofia, deveria ser mantido em sigilo. Mesmo os filósofos deveriam satisfazer-se em receber apenas as raízes desse conhecimento, enquanto o verdadeiro fruto seria proibido para eles, ou redigido em linguagem figurativa, acessível somente "aqueles que podiam saber". Isso porque era preciso proteger tais segredos de todo o risco de corrupção. Essa preocupação de Bacon em manter os conhecimentos do Secretum Secretorum fora do alcance "daqueles que não podem saber" era uma estratégia de poder, uma vez que ele compreendia que conhecimento era poder, devendo sua propriedade ser protegida a qualquer custo. Além disso, Bacon acreditava que o conhecimento não era apenas poder, mas também revelação divina. Por isso ele colocou o 
Secretum Secretorum como uma revelação de Deus para Adão, depois para os anjos, os profetas e para algumas personagens eleitas (LOCHRIE, 1999, p. 99).

Bacon atribuía o sucesso do Secretum Secretorum aos próprios segredos que ele carregaria, que seriam os maiores segredos naturais aos quais alguém poderia ter acesso na vida. A grande ironia, como aponta Lochrie (1999, p. 100), é que Bacon tinha uma enorme preocupação que tal conhecimento não se tornasse acessível "aqueles que não podem saber", porém o conteúdo do Secretum Secretorum já era de conhecimento e ampla discussão não entre os filósofos ou pensadores medievais, mas entre o público leitor mediano. Eram discussões que tratavam de temas como os diferentes tipos de ciências e medicina, conselhos políticos sobre realeza, justiça e a arte do bom governo, bem como informações acerca de regimes de saúde, além de temas de alquimia, magia, astrologia e fisiognomia, assunto que foi marcante também nas obras de Della Porta, tanto no De Furtivis Literarum Notis vulgo De Ziferis, quando tratava das características da face aplicáveis na comunicação secreta, chegando mesmo a dedicar uma obra ao tema ${ }^{5}$. William Eamon (2010) afirmou que o sucesso do Secretum Secretorum ante o público medieval derivou muito mais da promessa de poder, virtualmente ilimitado, sobre a natureza, os inimigos e mesmo contra a Fortuna, do que os temas dos quais tratava de forma direta. A possibilidade de aceder a esse poder e de tornar-se membro de uma elite formada pelos detentores desse conhecimento teria sido o grande atrativo do Secretum Secretorum para os leitores medievais. Lembre-se que, de acordo com Lochrie (1999, p. 103) o título árabe para essa obra poderia ser traduzido aproximadamente como O Livro da Ciência do Governo, sobre o bom ordenamento da arte de governar.

O texto que compunha o Secretum Secretorum adaptava uma conversa entre Aristóteles e Alexandre, o Grande, de maneira profundamente influenciada pela tradição esotérica árabe. A atribuição a Aristóteles de uma carta que intencionava revelar doutrinas secretas num momento em que começavam a fervilhar as traduções de obras aristotélicas, foi crucial para o sucesso do Secretum Secretorum. Assim o tratado ganhou credibilidade, legitimidade e autoridade oriundas do corpo de cartas apócrifas atribuídas a Aristóteles. Lochrie (1999) disse que os leitores medievais aceitavam a autenticidade do Secretum Secretorum, mesmo tendo em conta sua disparidade com o resto da filosofia aristotélica.

\footnotetext{
${ }^{5}$ Trata-se da De Humana Physiognomia Libri III, de 1586.
} 
Para além de garantir autenticidade ao tratado, essa tradição de cartas ainda trazia uma apropriação retórica da tradição oriental que duplicava a apropriação textual dos métodos esotéricos árabes. De uma forma geral trata-se de um conjunto de cartas onde Alexandre pedia conselhos a Aristóteles sobre diversos temas, bem de acordo com a natureza dos "espelhos de príncipes", a grande maioria sobre a melhor forma de governar seu império, chegando ao momento no qual o soberano demanda ao filósofo que este lhe revelasse o "segredo dos segredos". Se a princípio Aristóteles se mostrou disponível a aconselhar Alexandre, como sobre a melhor maneira de proceder em relação à conquista da Pérsia, o filósofo se mostrou deveras reticente em revelar o "segredo dos segredos". Primeiro ele se negou, alegando que tais segredos possuíam tal magnitude que o peito humano não poderia contê-los, apesar de este filósofo ser capaz de tal proeza. Depois de muita insistência por parte de Alexandre, Aristóteles relutantemente aceitou revelar-Ihe o Secretum Secretorum, contudo o faria através de uma linguagem figurativa, ou seja, através de uma escrita cifrada, por temer que tal conhecimento caísse nas mãos dos infiéis, "aqueles que não podem saber", uma vez que tais mistérios teriam sido revelados por Deus e eram capazes de permitir acesso direto a Ele (LOCHRIE, 1999, p. 101-102), retomando assim a máxima hermética de que somente é possível conhecer o Criador através de sua criação, pois esta estaria permeada de uma mensagem oculta de natureza divina.

A decisão do Pseudo-Aristóteles em escrever de maneira cifrada seria também uma estratégia para proteger o conhecimento do mestre e limitar as possibilidades de investigação do discípulo ${ }^{6}$. Além disso, as estratégias de segredo e de sigilo ampliavam o capital do Secretum Secretorum, mantendo-o a salvo dos olhos "daqueles que não podem saber", grupo que inclui o historiador dedicado a compreender o segredo e as sociabilidades que dele se originam. Portanto, esse secretismo expressa um esforço de defesa de um

\footnotetext{
${ }^{6}$ Essa relação entre mestre e discípulo como base da transmissão de um conhecimento cuja posse seria privilégio somente "daqueles que podem saber", nos remete à discussão conceitual que Antoine Faivre realizou acerca do conceito de Esoterismo. De acordo com Faivre (1994: 17-23), o Esoterismo ocidental poderia ser reconhecido pela presença de quatro características principais (Correspondência, Natureza Viva, Imaginação/Mediação, Experiência de Transmutação) e duas secundárias (Práxis da Concordância, Transmissão). O que pode ser percebido no discurso construído no Secretum Secretorum é a presença de várias dessas qualidades, uma vez que ele trata de temas como a dinâmica das qualidades ocultas do mundo natural, a influência astral no processo da vida sublunar, a capacidade de fazer renascer todo indivíduo que tivesse acesso às suas revelações, sua inserção numa tradição que remeteria à Antiguidade, e, talvez mais acentuadamente, a importância da mediação do mestre na relação entre o pupilo e esse conhecimento transcendental. Por isso mesmo, entendemos tal relação entre mestre e discípulo como uma relação de poder nos moldes foucaultianos
} 
conhecimento cuja posse implicava em poder. Ainda que não se saiba o real teor do pedido de Alexandre a Aristóteles, fica clara a valorização desse conhecimento, uma vez que o Pseudo-Aristóteles titubeou sobre o direito de o soberano ter acesso a ele. A escrita enigmática teria sido a saída para o Pseudo-Aristóteles cumprir múltiplos objetivos: respeitar suas obrigações para com soberano, revelando-lhe o que este desejava; proteger seu conhecimento de cair nas mãos "daqueles que não podem saber" e salvaguardar sua posição de poder na qualidade de único detentor de tal saber, e, além disso, proteger o segredo que Ihe foi revelado pela deidade. Num esforço de mesma natureza daquele realizado pelos secretários e pelos magos dos séculos XV e XVI (LOCHRIE, 1999, p. 103-104).

Para Lochrie (1999, p. 104-105), os esforços do Pseudo-Aristóteles em manter o seu conhecimento a salvo "daqueles que não podem saber", criava uma rede social cujos membros são reunidos pela exclusão do acesso à verdade última, dentre os quais está também o historiador. Conforme a análise de Danielle Jacquart e Claude Thomasset, o Secretum Secretorum seria mais uma obra de popularização de um discurso pseudocientífico, baseado na estrutura onde o mestre estaria numa posição de superioridade em relação ao discípulo, este possuidor de poder político. Por todo o Secretum Secretorum haveria mensagens "subtextuais" insinuando a superioridade do mestre perante o aluno, por exemplo, em sua capacidade de discernimento ou de bem aconselhar os reis.

A versão maior do Secretum Secretorum se dividia em torno de quatro eixos principais, sendo eles: a conduta e o comportamento adequados ao rei; as práticas da boa saúde; as propriedades das ervas e das pedras e, finalmente, a fisiognomia. Cada um desses tópicos se subdividia em um amplo leque de subtópicos. Na seção dedicada ao conselho do príncipe se discutiu um pouco de astronomia, seguido pelas questões pertinentes à prática da justiça real, da sabedoria, da bondade e da piedade. Assim, se aconselhava ao rei que reinasse com sabedoria, prudência, compaixão, providência e fé para que ele pudesse manter a obediência de seu povo. Também se aconselhava que ele promovesse a educação em seu reino, bem como se mantivesse saudável (LOCHRIE, 1999: 105-106).

Ao longo da Idade Média, o Secretum Secretorum tornou-se mais que um sinônimo de segredos esotéricos, contudo principalmente vinculado às práticas de sigilo que protegem o segredo. Uma vez que o Secretum Secretorum era capaz de se adaptar a diversos discursos, 
o que também ajuda a justificar o seu sucesso, ele foi utilizado para proteger profissões, elevar a autoridade dos filósofos e mistificar o lugar comum. Além disso, ele era capaz de traduzir, domesticar e instrumentalizar o segredo perigoso tanto para o Ocidente quanto para a comunidade cristã, notadamente o Oriente, o feminino e o judeu (LOCHRIE, 1999, p. 115-117).

Mais importante do que seu conteúdo esotérico, é o fato do Secretum Secretorum ser visto como ferramenta essencial ao governo, em duas das cortes mais importantes para o período, apresentando na Idade Média esse elo entre o bom governo e o conhecimento esotérico, bem como que as matérias relativas ao governo somente devem estar disponíveis "aqueles que podem saber", devendo ser protegidas a todo custo da curiosidade "daqueles que não podem saber". É nessa chave que compreendemos a crítica e a perseguição promovida pelo abade Johannes Trithemius às feiticeiras, visando proteger os príncipes do que o abade chamou de erros e de idolatria. $\mathrm{O}$ que de fato desejava o abade era garantir o monopólio sobre o pensamento esotérico que circulava na corte imperial (BRANN, 1999, p. 60). Conforme o abade, as feiticeiras "barulhentamente capturam a atenção de reis e príncipes, corrompem a fé ortodoxa, destroem a pureza de nossa religião, e reintroduzem idolatria" 7 (BRANN, 1999, p. 60), num claro esforço por garantir que o monopólio sobre o segredo e o oculto ficasse restrito a ele. Uma vez que tais conhecimentos eram ferramentas de poder, como se percebeu com o caso do Secretum Secretorum, Trithemius buscou garantir a posse deles.

Trithemius defendia que o métier principesco tinha uma afinidade natural com o esoterismo. Na carta de vinte e seis de junho de 1503 endereçada a Joaquim de Brandemburgo, o abade alemão buscou defender-se das acusações de demonomagia que o perseguiam desde os ataques de Carolus Bovillus ou Charles de Bovelles, afirmando que os príncipes do passado foram capazes de acumular riqueza, honra, felicidade e fama imortal ao se instruírem no conhecimento esotérico, possibilidade ao alcance dos príncipes de seu tempo. Ao escrever para Maximiliano I, em vinte e seis de abril de 1508, Trithemius disse que os príncipes detinham as qualidades requeridas para a iniciação no saber esotérico, uma vez que combinavam "dignidade real com uma aguda capacidade mental, disposição

\footnotetext{
${ }^{7}$ noisily catch the attention of kings and princes, corrupt the orthodox faith, destroy the purity of our religion, and reintroduce idolatry.
} 
virtuosa, e excepcional educação" 8 (BRANN, 1999, p. 106). Matthias da Hungria (BRANN, 1998, p. 106-107) foi mais uma vez lembrado pelo abade como exemplo desse tipo de príncipe. Contudo, não era uma relação de isonomia, uma vez que o abade se colocava como mestre tendo o príncipe como discípulo. Assim, como fez o Pseudo-Aristóteles em relação a Alexandre, Trithemius se propunha a iniciar ao princeps, contudo ele estaria no controle da situação, delimitando o acesso de seu pupilo a esse conhecimento que implicava em poder. Era um esforço para inverter a ordem estabelecida, o príncipe era submetido à autoridade do mestre esotérico, ao menos no discurso deste. Ao manter-se senhor de um conhecimento que o príncipe almejava, ele obtinha autoridade sobre o soberano.

Essa relação de poder mediada pelo segredo, onde se buscava submeter o príncipe a autoridade de um mestre do secretismo, pautada pela aquisição de um conhecimento de natureza esotérica, será vista novamente através das relações entre os secretários e os seus senhores, relação esta mediada pelo domínio da comunicação secreta, esta profundamente envolvida pela concepção esotérica de segredo, ou seja, de que a natureza foi construída em camadas, entre as quais o Criador ocultou sua mensagem divina e secreta. Uma vez mais, podemos perceber a influência da concepção esotérica de segredo atuando na formação de um tipo de segredo político que seria fundamental para a complexa transição entre o regimen animarum medieval e a Razão de Estado.

João de Viterbo (c.1255-1308), em seu Liber de regimen civitatum, ao tratar do termo latino regimen já se preocupava com a polissemia de tal palavra no ambiente medieval, conforme Senelart (2006, p. 26) apontou:

(1) Regimen significa primeiramente a direção (gubernatio) da cidade, como a do navio para o marinheiro: consiste na utilização dos meios apropriados para conduzir a cidade, assim como o piloto se serve do leme e do mastro para manter sua rota. (2) Designa igualmente a ação de conter (sustentatio) os homens, como se freia um cavalo com a rédea para impedir que sua velocidade o lance num precipício, (3) a justa medida (temperies) que devem se impor os que entram em cólera excessiva (essa regra se aplica particularmente aos juízes), (4) a moderação (moderatio), não na acepção precedente, mas enquanto ato de conduzir, dirigir o homem para afastá-lo do mal; também aqui o termo é empregado para a condução do cavalo cuja marcha é regulada pela rédea. (5) Chama-se regimen, além disso, a guarda ou proteção atenta (custodia) da cidade (passagem do vocabulário náutico ou equestre da condução ao militar da vigilância, sem nenhuma conotação pastoral), (6) a ação de reger ou dirigir (regere) - esta aí, segundo o autor

\footnotetext{
${ }^{8}$ who combined Royal dignity with an acute mental capacity, virtuous disposition, and exceptional education.
} 
que evoca a etimologia de Isidoro de Sevilha, (7) o governo, (8) enfim a administração da cidade (administratio), não enquanto órgão mas enquanto dignidade (honor municipalis).

Contudo, uma ideia se sobrepõe a todas as possibilidades de sentido, sendo ela a do regimen animarum. De acordo com o pensamento político medieval, o monarca não possuía o poder, este lhe era apenas concedido de forma que ele pudesse garantir que todas as almas da Cristandade conseguissem obter a salvação, ou seja, que pudessem adentrar a Jerusalém celestial. O poder era apenas e tão somente a ferramenta empregada para tal atividade. $\mathrm{O}$ que a historiografia tem discutido já há algum tempo é que, a partir do século XIV, principia uma transformação na relação dos homens com o poder. Se antes, ele era mera ferramenta, agora em diante ele se tornaria o objeto central das atenções. De meio ele se tornava um fim em si mesmo. Um dos primeiros autores a se debruçar sobre esse objeto foi Francesco Guicciardini (1483-1540) em seu Dialogo del Reggimento di Firenze, composto entre 1521 e 1526. Para Guicciardini, havia uma clara diferença entre a "arte do Estado" e a "arte da Política", conforme nos aponta Maurizio Virolli (2002, p. 179):

A primeira é uma extensão da economia; a segunda como temos visto, foi entendida como uma derivação da ética e da lei. A arte do estado foi amplamente a arte de consolidar e criar lealdades privadas; esforços políticos para restringir lealdades privadas e reforçar ligações impessoais, como o amor pela liberdade, justiça e pátria. (VIROLLI, 2002, p. 179) ${ }^{9}$

A imagem surgida das discussões de Guicciardini nos dão a dimensão das transformações presentes na passagem da prática de uma "arte política", o regimen animarum medieval, para uma "arte do Estado", a nascente Razão de Estado. Enquanto a primeira tem um caráter coletivista, a segunda é iminentemente privada; a primeira deve ser exercida tendo no horizonte objetivos que contemplem o interesse comum, que para o "homem medieval" poderia ser resumido pela ideia de que cada um deve ter acesso garantido ao que lhe cabe e nada mais, a segunda é pensada a partir de relações pessoais e interesses particulares que não encontram problemas ou constrangimentos em se sobrepor à "busca pelo bem comum". Nesse sentido, a ideia apresentada pelo Secretum Secretorum é particularmente poderosa, uma vez que distinguir os indivíduos entre "aqueles que não podem saber" e "aqueles que podem saber" cria uma relação hierarquizante entre eles, cuja

\footnotetext{
${ }^{9}$ The former is an extension of economics; the second as we have seen, was understood as a derivation of ethics and law. The art of the state is largely the art of consolidating and creating private loyalties; politics strives to restrain private loyalties and reinforce impersonal attachments, such as the love for liberty, justice and country.
} 
fonte de poder está na contraposição de conhecimento e ignorância. Nesse ambiente de personalização das relações com o poder, a ideia de que a posse de um conhecimento secreto era uma vantagem na busca por "criar, conquistar e consolidar Estados", foi se solidificando de tal maneira que as estratégias de sigilo e de segredo foram ocupando um lugar cada vez mais central nas práticas de natureza política. Assim, o Secretum Secretorum acabou por semear o solo no qual frutificariam posteriormente várias formas de relações políticas pautadas pelo segredo que eram formatadas ou diretamente oriundas do esoterismo que marcou tão profundamente o chamado Renascimento dos séculos XV e XVI.

\section{REFERÊNCIAS BIBLIOGRÁFICAS}

FONTES PRIMÁRIAS

Giambattista DELLA PORTA. De Furtivis Literarum Notis vulgo De Ziferis - Libri III. Neapoli: Apud loa Mariam Scotum, 1563.

Giambattista DELLA PORTA. De Occultis Literarum Notis, Sev Artis Animi Sensa Occulte Aliis Significandi. Argentorati: Impensis Lazari Zetzneri Bibliop., 1606.

Johannes TRITHEMIUS. Polygraphiae libri sex, loannis Trithemii Abbatis Peapolitani, quondam Spanheimensis, ad Maximilianum Caesarem. Oppenheim: Haselberg, 1518.

Johannes TRITHEMIUS. Steganographie: Ars per occultam Scripturam animi sui voluntatem absentibus aperiendi certu, 4to, Darmst. 1621

BIBLIOGRAFIA SECUNDÁRIA

BAILEY, Michael D. The meanings of magic. Magic, Ritual, Witchcraft, 2006, p. 1-23.

BETHENCOURT, Francisco. O imaginário da magia: feiticeiras, adivinhos e curandeiros no século XVI. São Paulo: Companhia das Letras, 2004.

BLACK, Antony. El pensamiento politico en Europa, 1250-1450. Cambridge: Cambridge University Press, 1996.

BOUDET, Jean Patrice \& Véronèse, Julien. Le secret dans la magie rituelle médiévale. Micrologus: Natura, Scienze e Società Medievali. Florença: SISMEL - Edizioni Del Galluzo, 2006, no XIV.

BOUDET, Jean-Patrice. Pour commencer bonne maniere de gouverner ledit royaume." Un miroir du prince du $\mathrm{xv}^{\mathrm{e}}$ siècle : I'avis à Yolande d'Aragon. In : LACHAUD, Frédérique \& SCORDIA, Lydwine. Le Prince au miroir de la littérature politique de l'Antiquité aux Lumières. Mont-Saint-Aignan: Publications des universités de Rouen et du Havre, 2007.

BRANN, Noel L. The Abbot Trithemius (1462-1516): the renaissance of monastic humanism. Leiden: Brill, 1981.

BRANN, Noel L. Trithemius and Magical Theology: A Chapter in the Controversy over Occult Studies in Early Modern Europe. New York: State University of New York Press, 1999. 
BRANN, Noel L. Was Paracelsus a disciple of Trithemius? Sixteenth Century Journal, v. 10, n. 1, Spring, 1979, p. 70-82.

BUBELLO, Juan Pablo. Esoterismo y política de Felipe II en la España del Siglo de Oro. Reinterpretando al círculo esotérico filipino en El Escorial: Juan de Herrera, Giovanni Vicenzo Forte, Diego de Santiago, Richard Stanihurst. Veredas da História, v. III, n. 2, 2010.

BURKE, Peter; PORTER, Roy (orgs.). História social da linguagem. São Paulo: UNESP, 1997.

CASSIRER, Ernst. Indivíduo e cosmos na filosofia do Renascimento. São Paulo: Editora Martins Fontes, 2001.

CLARK, Stuart. Pensando com demônios: a ideia de bruxaria no princípio da Europa Moderna. São Paulo: Edusp, 2006.

CORSETTI, Jean-Paul. História do esoterismo e das ciências ocultas. Braga: Círculo de Leitores, 2004.

COULIANO, loan P. Eros and magic in the renaissance. Chicago: University of Chicago Press, 1987.

EAMON, William. Masters of fire - italians alchemists in the court of Philip II. In: LÓPEZ-PÉREZ, Miguel; KAHN, Didier; REY-BUENO, Mar (eds.), Chymia: Science and Nature in Medieval and Early Modern Europe. Cambridge: Cambridge Scholars Publishing, 2010, p. 138-156.

EBERLE, Patricia. Mirror of Princes. In: STRAYER, Joseph. Dictionary of the Middle Ages. New York: Charles Scribner's Sons, 1987.

FAIVRE, Antoine. O Esoterismo. Campinas; São Paulo: Papirus, 1994.

GARIN, Eugenio. Idade média e renascimento. Lisboa: Editorial Estampa, 1994.

GARIN, Eugenio. O zodíaco da vida: a polêmica sobre a astrologia do século XVI. Lisboa: Editorial Estampa, 1998.

GRÉVIN, Benoît. Le parchemin des cieux: essay sur le Moyen Âge du langage. Paris: Éditions du Seuil, 2012.

JUCKER, Michael. Secrets and politics: methodological and communicational aspects of late medieval diplomacy. Micrologus: Natura, Scienze e Società Medievali. Florença: SISMEL - Edizioni Del Galluzo, 2006, n. XIV.

KELLENBENZ, Hermann. Finanze e ragion di Stato nel primo período dell'epoca moderna. In: DE MADDALENA, Aldo; KELLENBENZ, Hermann (orgs). Finanze e ragion di Stato in Italia e in Germania nella prima Età moderna. Bologna: Società editrice il Mulino, 1984.

KIECKHEFER, Richard. Magic in the Middle Ages. Cambridge; New York: Cambridge University Press, 1989.

KIECKHEFER, Richard. The specific rationality of medieval Magic. The American Historical Review, v. 99, n. 3, jun., 1994, p. 813-836.

KRYNEN, Jacques. Idéal du prince et pouvoir royal en France à la fin du Moyen âge: 1380-1440: étude de la littérature politique du temps. Paris : A. et J. Picard, 1981. 
LACHAUD, Frédérique \& SCORDIA, Lydwine. Le Prince au miroir de la littérature politique de l'Antiquité aux Lumières. Mont-Saint-Aignan: Publications des universités de Rouen et du Havre, 2007.

LOCHRIE, Karma. Covert operations: medieval uses of secrecy. Philadelphia: University of Pennsylvania Press, 1999.

PINGREE, David. Learned magic in the Time of Frederick II. Micrologus: Natura, Scienze e Società Medievali. Florença: SISMEL - Edizioni Del Galluzo, 1994, n. II.

SKINNER, Quentin. As fundações do pensamento político moderno. São Paulo: Companhia das Letras, 1996.

TANNIER, Bernard. L'hermétisme à la Renaissance. In: LAROQUE, François (ed.). Histoire et secret à la Reniassance. Paris: Presses de la Sorbonne Nouvelle, 1997.

ULLMANN, Walter. Historia del pensamiento político en la Edad Média. Barcelona: Editorial Ariel, 1999.

VERGER, Jacques. Homens e saber na Idade Média. Bauru/SP: EDUSC, 1999.

VÉRONÈSE, Julien. La notion d'«auteur-magicien» à la fin du Moyen Âge: Le cas de l'ermite Pelagius de Majorque († v. 1480). Médiévales. [En ligne], 51, automne 2006.

VIROLI, Marurizio. From politics to reason of state: the acquisition and transformation of the language of politics (1250-1600). Cambridge: Cambridge University Press, 1992.

WALKER, D.P. Spiritual \& demonic Magic: from Ficino to Campanella. Pennsylvania: The Pennsylvania State University Press, 2000.

WARBURG, Aby. O renascimento do paganismo antigo (Traduzido por Cássio da Silva Fernandes de WARBURG, Aby. Die erneuerung der heidnioschen antike. Leipzig; Berlin: B.G. Teubner, 1932. Cotejada com a edição italiana: Emma Cantimori (trad.). La rinascita del paganesimo antico. Firenze: La Nuova Itália Editrice, 1996).

WEILL-PAROT, Nicolas. Encadrement ou dévoilement-l'occulte et le secret dans la nature chez Albert le Grand et Roger Bacon. Micrologus: Natura, Scienze e Società Medievali. Florença: SISMEL - Edizioni Del Galluzo, 2006, n. XIV.

WILLIAMS, Steven J. The early circulation of the pseudo-aristotelian Secret of Secrets in the west: the papal and imperial courts. Micrologus: Natura, Scienze e Società Medievali. Florença: SISMEL Edizioni Del Galluzo, 1994, n. II.

WOLFF, Phillippe. Outono da idade média ou primavera dos tempos modernos? São Paulo: Martins Fontes, 1988.

YATES, Frances Amelia. Giordano Bruno e a tradição hermética. São Paulo: Cultrix, 1995.

ZAMBELLI, Paola. White magic, black magic in the European Renaissance. Leiden, Boston: Brill, 2007. 